\title{
ENTRE RETICENCIA E INSISTENCIA: LA REVOLUCIÓN SEXUAL INACABADA DE DORIS LESSING EN THE GOLDEN NOTEBOOK ${ }^{1}$
}

\author{
Francisco José Cortés Vieco²
}

Resumen: Entre dolor y placer, demencia y recuperación mental, The Golden Notebook de Doris Lessing es un compendio enciclopédico y literario sobre la introspección psicológica, la autonomía asertiva con fines reivindicativos, la despenalización ideológica y la desmitificación artística de la sexualidad femenina en Inglaterra durante la segunda mitad del siglo XX. No obstante, esta obra polifónica y poliédrica se debate entre su empuje pionero como panacea de la Revolución Sexual en este período y su reserva al proclamar el hito histórico de la equiparación de los derechos civiles, fisiológicos y emocionales de la mujer contemporánea con respecto a los del hombre.

Palabras clave: sexualidad, mujer, hombre, amor, coito, liberación, dependencia, locura.

Title in English: Between Reluctance and Insistence. The Incomplete Sexual Revolution in The Golden Notebook by Doris Lessing

Abstract: Ranging from pain to pleasure, madness to mental recovery, British writer Doris Lessing's The Golden Notebook is an encyclopaedic, literary compendium regarding women's psychological introspection, self-assertion, and search for validation, ideological decriminalization and aesthetic demythologizing of female sexuality in post-war England. Nevertheless, this polyphonic, polyhedral novel struggles between its decisive impetus towards the 1960s Sexual Revolution, and the author's alleged reluctance to proclaim -by comparison with the powerful position of men- the historical landmark of women's egalitarian rights in terms of social status, bodily enjoyment, emotional fulfilment and independence.

Key words: sexuality, woman, man, love, coitus, emancipation, dependence, madness.

${ }^{1}$ Fecha de recepción: 26/09/2013

Fecha de aceptación: 21/11/2013

${ }^{2}$ Profesor Asociado, Departamento de Filología Inglesa, Universidad Autónoma de Madrid, España; $\square$ francisco.cortes@uam.es. 


\section{Introducción}

Desde tiempos inmemoriales, la regulación de la definición ontológica, la anatomía, la conducta y los roles sociales de la mujer, así como de sus procesos cognitivos, mentales y afectivos, ha sido un pilar fundacional de la arquitectura patriarcal con el fin de anestesiar y someter a la población femenina con el consiguiente beneficio utilitario para sus instituciones y miembros masculinos. La sexualidad ${ }^{3}$ ha sido, sin duda, la esfera de su patrimonio genético y humano más reglamentada y ahogada por ideologías hegemónicas con intensidad misógina a lo largo de nuestra historia. Ya en el siglo XX, existen teorías científicas que indican que la supresión de la libido de la mujer constituye un fenómeno cultural asentado sobre dos hipótesis nulas: su menor deseo erótico y el alto coste del coito para ella por la amenaza del embarazo ${ }^{4}$ (Baumeistery Twenge 2002: 167). Además, ambas integrarían el discurso normativo del hombre que encubre su inseguridad generada por la multiplicidad orgásmica de su compañera, quien demandaría un mayor número de encuentros genitales entre ambos (2002: 169). No obstante, la mujer también decidiría restringir su disponibilidad sexual para obtener mayores ganancias y un mejor trato por parte de su pareja (2002: 171).

Bajo el paraguas del movimiento feminista para la obtención de la igualdad de derechos sociopolíticos de la mujer en relación a los del hombre, el período histórico de la llamada Revolución Sexual, entre la década de los sesenta y los ochenta del siglo XX en Europa y América, abogará por la permisividad y la normalización del control y el disfrute de la sexualidad femenina contra la ancestral extirpación quirúrgica de su deseo erótico y su placer corporal por una medicina y una psiquiatría en manos de creadores varones: científicos y facultativos. Michel Foucault resaltará la desaceleración en la represión de las relaciones pre- y extramatrimoniales, a la par con la eliminación parcial de la condena a las perversiones sexuales durante el siglo pasado (1976: 115). A su vez,

\footnotetext{
${ }^{3}$ Sexualidad nace como vocablo en el siglo XIX y se vincula con el desarrollo de diversos campos del conocimiento y normas sancionadas por instituciones médicas, pedagógicas, religiosas y judiciales sobre la conducta, deberes, placeres, sentimientos, sensaciones y sueños del individuo (Foucault 1984: 3-4).

${ }^{4}$ Para mayor fluidez del discurso, opto por traducir al castellano las citas procedentes de fuentes secundarias. Sin embargo, aquéllas que pertenezcan a fuentes primarias permanecerán en inglés.
} 
amparada por la solución clínica de los métodos anticonceptivos y por la relajación de contracturas morales y religiosas, la mujer accederá gradualmente al mundo laboral y a la educación universitaria, lo cual favorecerá a la libre circulación de su deseo sexual, que será manifiestamente ilustrado en una literatura con manufactura propia desde la segunda mitad del siglo XX. Este producto cultural no sólo cuestionará la doble moral imperante en la sociedad del momento, detectará sus incurables tumores y reflejará los hitos paulatinamente logrados por la mujer en el curso de su interacción con la realidad cotidiana, sino que también conectará el desorden psíquico con su cuerpo y explorará la multiplicidad de la sexualidad más allá de la genitalidad. Sin embargo, continuará padeciendo el influjo masculino sobre su experiencia como mujer y escritora. En el panorama académico y literario de Reino Unido y los Estados Unidos en esta época, la irrupción de la libido femenina será legitimada por los ensayos feministas de Simone de Beauvoir, Betty Friedan y Kate Millett, la publicación de Lady Chatterley's Lover de D. H. Lawrence tras una larga censura por sus explícitas escenas de adulterio, o la osada prosa de Henry Miller, Vladimir Nabokov, Anaïs Nin y Doris Lessing.

\section{La embrionaria proposición sexual de Doris Lessing}

Sin desmerecer las tentativas artísticas de las corrientes matrilíneas y sororales de sus predecesoras desde el siglo XIX -Kate Chopin, Edith Wharton o Virginia Woolf-, la prosa revolucionaria y corrosiva de la escritora británica Doris Lessing (1919-2013), Premio Nobel de Literatura en 2007, será pionera al no sólo aproximarse, sino asaltar y poseerla narrativa de la sexualidad femenina con plenas facultades y derechos. Hasta entonces, esta temática era un fortín artístico casi virgen, no acotado, dilatado y aún en vías de liberación desde manos masculinas. Gracias a ella, la mujer gobernará esta conquista y la entenderá como fenómeno global que integraría aspectos biológicos, sociales y psicológicos de su vida, tanto en una vertiente subjetiva con ecos intimistas y 
confesionales, como en sus ramificaciones genéricas que mimetizan la experiencia del colectivo femenino en el convulso contexto espaciotemporal de esta autora.

Nacida en la antigua Persia, de padres británicos, y criada en Rodesia, hoy Zimbabue, Doris Lessing desembarcó con treinta años en Inglaterra en 1949 como militante de izquierdas, mujer independiente y separada con un hijo, fruto de su segundo matrimonio. Si bien su debut literario bajo los auspicios de Martha Quest -su heroína autobiográfica de la pentalogía The Children of Violence- se nutre de sus vivencias en África, sus obras posteriores de corte experimental durante los sesenta no se encerrarán en el microcosmos de la inmigrante que choca contra la madre patria, aunque sí sugerirán análogas sensaciones de extranjería, exclusión y beligerancia sufridas por la mujer anglosajona en su hábitat natural. De hecho, la crónica de su evolución narrativa en esta década -anterior y coetánea a la Revolución Sexual y la lucha feminista por la igualdad entre sexos- indaga en la salud mental y el placer corporal de personajes femeninos inmersos - como ella- en esta misma vorágine cultural, que es antesala del mundo contemporáneo. Por un lado, su prosa transcurrirá en paralelo al movimiento de la antipsiquiatría de Dr. Laing ${ }^{5}$, quien diagnosticará que la esquizofrenia es una respuesta coherente y curativa a los complejos imperativos de la vida moderna (Showalter 1985: 238). Por otro, dialogará con la denuncia sociológica de la activista estadounidense Betty Friedan quien, en The Feminine Mystique (1963), asedia al reinante mito domesticidad de la feliz ama de casa de posguerra que vive en los suburbios de grandes urbes, digna heredera del ángel del hogar ${ }^{6}$ victoriano.

Para propiciar la erupción textual de la sexualidad desde la conciencia femenina la pluma de Doris Lessing, analizaré su obra The Golden Notebook (1962) dentro de su contexto histórico y el conjunto de su corpus literario ${ }^{7}$. Denominaré esta temática paracultural al situarse adyacente a la Inglaterra de posguerra como anexo periférico de

\footnotetext{
${ }^{5}$ Con Divided Self (1960) y Sanity, Madness, and the Family (1964) de gran éxito en los sesenta, Dr. R. D. Laing abandera la antipsiquiatría que critica las opresoras prácticas clínicas de los sanatorios mentales. ${ }^{6}$ Término derivado del poema The Angel in the House (1854) del artista Coventry Patmore como epítome del ideal de feminidad victoriana que asigna a la mujer preceptivos roles de domesticidad.

${ }^{7}$ The Golden Notebook dialogaría, en especial, con The Four-Gated City (1969), último volumen de la pentalogía The Children of Violence, que aborda la emancipación sexual de su heroína, además de reflejar una visión apocalíptica del futuro desde la locura y sucesos sociopolíticos del presente histórico.
} 
embrionaria emancipación de la mujer para cruzar tabús ideológicos, lograr su plenitud orgásmica y su integración oficial como ciudadana de primera clase en la sociedad. Sin embargo, se encontrará todavía en tangencia con el continuismo androcentrista que persiste impune en las relaciones asimétricas entre los dos sexos durante esta misma época. Si bien el trastorno psicológico es el eje fundacional de esta creación literaria, optaré por la exploración en el tratamiento -no secundario- de la sexualidad femenina.

La pluralidad estética y estilística de The Golden Notebook -(auto) biografía, novela, sucesión de historias cortas, periodismo, documental, crítica literaria y propaganda política- se aúna a su disgregado material enciclopédico y sinfonía coral para diseccionar estados emocionales, preocupaciones sociopolíticas y acontecimientos del siglo XX: la huella física y psíquica de la reciente Segunda Guerra Mundial, el desmembramiento del comunismo y el nacimiento de la New Left, la lucha de sexos, los conflictos entre padres e hijos, tensiones coloniales y raciales. Además sobrevolará por el proceso literario desde su gestación hasta su recepción, pasando por el llamado bloqueo creativo del autor. Asimismo, Doris Lessing abrirá la caja de Pandora a una prosa en torno a la sexualidad femenina -ya incontenible y torrencial-, que distorsiona los coletazos del aún vigente sustrato patriarcal de misoginia y puritanismo anacrónico en el pensamiento occidental. Para ello, reflejará el aprendizaje de unas heroínas que (sobre/con) viven con su realidad biológica, comparten sus vivencias amatorias con el lector y amadrinan la satisfacción de su libido ante sus amantes masculinos mediante acciones, descripciones y diálogos con explícito contenido erótico. No recurrirá a la tradición literaria de metáforas y símbolos equívocos para referirse a esta temática que aún se consideraba un tácito veto artístico. Por un lado, The Golden Notebook irritará a intelectuales del Establishment porque expresaría el resentimiento sexual y social de Doris Lessing hacia los hombres, a los que "rechaza y manipula" (Burguess 1967: 122). Por otro, su publicación será crucial para consolidar la segunda ola de feminismo en los sesenta (Greene 1994: 19). Será celebrada por simpatizantes que definirán esta obra como "el primer tampax de la literatura universal" (Du Plessis 1980: 10). Pese a convertirse en vademécum de este movimiento, la propia autora advertirá en su prefacio que, sin dejar de apoyar esta causa ni querer perjudicarla, la locura -no la guerra entre 
sexos- es el tema principal de una novela que no debería catalogarse como "trompeta del feminismo" (1972: 8).

El intrincado esqueleto estructural y argumental de The Golden Notebook es la historia corta llamada "Free Women" con narradora omnisciente. Se divide en cinco partes y está protagonizada por Anna Wulf. Con más de treinta años, esta heroína es una mujer divorciada que emigró desde África a Inglaterra acompañada de su hija pequeña Janet tras la Segunda Guerra Mundial. Escritora que padece el bloqueo creativo, el éxito de su única obra publicada, Frontiers of War, garantiza su independencia económica. Vive en Londres junto a su amiga Molly, también separada y con un hijo adolescente. Ambas son activistas comunistas y pacientes de psicoterapia. Las cuatro primeras secciones de este relato se fraccionan en cuatro cuadernos escritos en primera persona ${ }^{8}$ durante los años cincuenta. Abarcan facetas diferenciadas -incluso disociadas y contradictorias- de la subjetividad y la realidad externa de Anna Wulf: el negro sobre sus crónicas africanas y su carrera literaria en la capital británica; el rojo sobre su afiliación y posterior desilusión con el partido comunista; el amarillo como manuscrito de su novela no editada The Shadow of the Third en torno a las aventuras sexuales y amorosas de Ella -su heroína autobiográfica-; y el azul sobre aspectos de su vida cotidiana y sus propios desengaños sentimentales. Antes de finalizar la quinta parte de su historia, reemplazará estos diarios fronterizos por otro aglutinante y de color dorado con varios fines terapéuticos: retomar la escritura y propulsar un giro en su vida para reunificar los fragmentos de su Yo quebrado y su experiencia dividida con anterioridad en cuatro compartimentos. En este artículo, me limitaré a desgranar la temática de la sexualidad femenina contenida principalmente en el diario amarillo, así como en pasajes del azul y el relato corto dentro de The Golden Notebook.

\footnotetext{
${ }^{8}$ La excepción será el cuaderno amarillo, el único que está escrito en tercera persona.
} 


\section{La mujer habla de/ experimenta con el sexo}

Doris Lessing retratará a Anna y Molly como paradigmas de mujeres liberadas, aunque aún cautivas dentro de un contexto para-cultural aún poco halagüeño. Demostrarán que existe vida tras el divorcio y que disfrutan del coito sin cumplir su primigenia misión reproductiva. Pero ambas rivalizan con la figura oficial, inamovible y casta de la esposa a quien sus maridos nunca abandonarán, aunque escapen furtivamente del hogar para evacuar sus instintos eróticos gracias a deseables y disponibles sustitutas como las dos heroínas. Si para ellas libre expresa su independencia financiera y la elección de sus relaciones sentimentales, este término define su promiscuidad para los hombres y les habilita a tratar a sus queridas sin respeto, honestidad ni ternura (Spencer 1973: 253). Las protagonistas de Free Women romperán tabúes y conseguirán dialogar sobre sexo con Richard, exmarido de Molly, obsesionado por satisfacer su placer genital: “There's one problema you haven't got -it's a purely physical one. How to get an erection with a woman you've been married to fifteen years?" (Lessing 1962: 48). Hastiado por la rutina conyugal, encadenará affaires con sus jóvenes secretarias bajo el axioma de que cuanto más numerosos y recientes sean estos escarceos, mayor goce le proporcionarán. Anna y Molly le reprocharán su indiferencia con respecto al daño psíquico infligido a su segunda esposa, Marion. Le definirán como egoísta porque alentó su romance con otro hombre y después la sedujo al saber que estaba a punto de abandonarle. Pero, ante todo, la amiga de su exmujer aprovechará esta ocasión para burlarse con ironía de los comentarios despectivos de Richard en relación con su aspecto físico, ya que estarían fundados en la negativa de la joven a engrosar su lista de conquistas: "He said: Anna, you should take more care of yourself, you're looking ten years older than you should, you are getting positively wizened. So I said, But Richard, if I'd said to you, Oh yes, do come into bed, at this very moment you'd be saying how beautiful I was" (1962: 60). Sin embargo, esta fortaleza dialéctica difiere de su fragilidad emocional -a solas, con su cuaderno azul-, cuando intenta asimilar el abandono de su amante Michael y suturar la herida psíquica abierta por éste. 
Plasmado en esta obra, el pesimismo de Doris Lessing relativo al éxito de la causa feminista surge de su convicción de que el libre acceso y el usufructo de la mujer a su propia sexualidad desinhibida no entrañan su emancipación del hombre y la sociedad. Pese a la apología de la autonomía femenina, el inicial fervor comunista y la devoción maternal de Anna, el amor heterosexual hacia un señor casado será el único motor de su vida: "I don't care a damn about politics or philosophy or anything else, all I care about is that Michael should turn in the dark and put his face against my breasts" (Lessing 1962: 271). Su pronóstico reservado será el latente peligro de la pérdida de su propia identidad y su dependencia autodestructiva del hombre. De hecho, la autora de The Golden Notebook diagnosticará la rabia de su heroína por no llevar una vida convencional, y desvelará su sueño romántico: una relación monógama, no necesariamente bendecida por una boda, con un compañero protector, cariñoso y fiel. Pero sus relaciones amorosas amalgamarán emociones contrapuestas: desde resentimiento, odio y pánico ante la previsible deserción de su amante, hasta idolatría, servilismo y satisfacción sexual. Anna revelará que la primera vez que alcanzó el orgasmo fue de la mano de Michael tras su infeliz matrimonio con Max. Con éste último, el coito únicamente cumplió con su función tradicional de procrear y nutrió sus temores de ser frígida por la mutua incompatibilidad entre ellos. Mediante Frontiers of War, su best-seller en un contexto bélico, africano y autobiográfico, su heroína relata el episodio en el que su marido conoce su infidelidad con un amigo de la pareja -plausible causa de su fracaso conyugal- que quedará paradójicamente grabado en su memoria como único recuerdo de sexo marital: "The only time I could remember him making love to me with any conviction was when he knew I had just made love to someone else [...] We never forgave each other for it... So a 'sexless' relationship was ended finally, by sex" (Lessing 1962: 148).

Será fundamentalmente en el cuaderno amarillo donde Doris Lessing, a través de su ejecutora Anna Wulf, exponga el universo amoroso y erótico del álter ego de ésta última: Ella. De este modo, desnudará zonas más íntimas -erógenas y dolorosas- de ellas tres como mujeres reales o ficticias. Numerosas obras de la literatura femenina del siglo XX obedecen a la confrontación de sus creadoras con traumas propios para 
esconder o exhibir tintes autobiográficos. Al acuñar el concepto de escritoterapia, Suzette Henke señala que el acto de transcribir su propia vida contiene un potencial curativo para su autora (2000: xv). Esta estrategia literaria actuaría como costura que sutura fisuras originadas por traumatismos físicos y psíquicos sufridos en primera persona. Por consiguiente, canalizaría la expresión manuscrita del sufrimiento, crisis emocionales, episodios de transgresión y victimización verbalmente impronunciables gracias a la máscara de la ficción, que operaría como espacio protector de repetición para que la escritora pueda separarse de la heroína creada y del lector anónimo al que se dirige (2000: xviii-xix). Ella, divorciada y con un hijo pequeño, trabaja en una revista femenina y escribe una novela sobre el suicidio. Conocerá y se enamorará del psiquiatra Paul Tanner, otro hombre casado. Pese a admitir su insensibilidad física y su caparazón de autocontrol para evitar el dolor psíquico que prevé ante su inminente ruptura con Michael, Anna instrumentalizará a su criatura inventada para dar rienda suelta a su paroxismo emocional y prepararse para ser, en breve, abandonada (Brooks 1973: 105). En un extremo, Ella personificaría su necesidad psicológica de estabilidad sentimental con un único hombre y su fantasía romántica de hallar el amor verdadero. En el otro, Paul deduce que su nueva conquista debe ser tan promiscua como él al pertenecer a su misógina acepción de la mujer libre, mientras le invita a renovar una cita amatoria: “'So you'll be free tonight, Ella'. 'What do you mean, free?' 'Oh... for your other boyfriends, you've been neglecting them, haven't you?'” (Lessing 1962: 189). Al igual que otros personajes masculinos adúlteros y oportunistas en la obra, este psiquiatra de mediana edad se resiste al cambio de estado civil -casado-, y a dar una oportunidad a su amante. Como secuela del trauma de la reciente guerra y de forma descontextualizada, Doris Lessing enlazaría esta aparente frialdad sentimental y la común despreocupación del hombre moderno con el miedo latente al conflicto armado de quien evita atar lazos emocionales con el prójimo, ya que se arriesga a perder después a sus seres queridos.

De la misma manera que su creadora Anna, Ella confesará a su amiga Julia haber experimentado por primera vez el placer sexual en brazos de Paul y nunca con su exmarido. Durante su primer coito, llegará a superar su puritanismo y aversión hacia su propia anatomía femenina, la cual visualiza, acepta y aprecia gracias al experto donjuán: 
"She laughed, without hurt, because the way his hand lay on her flesh told her he liked her as she was. And she liked herself, naked. [...] Often she had wanted to be different, had longed to be larger, fuller, rounder, 'more of a woman', but the way his hand touched her cancelled all that and she was happy" (Lessing 1962: 182-183). Esta sensación de plenitud física contrasta con su depresión post-coital y el perpetuo estado de ansiedad ante cada nuevo rendez-vous con su amado. Ventrílocua de Anna y Doris Lessing, será Ella quien articule la máxima hipocrática sobre la sexualidad femenina en The Golden Notebook que se sustenta en una comunión indisoluble entre instinto sexual y amor que encadena a la mujer a su dependencia emocional del hombre: "Free, we say, yet the truth is they get erections when they're with a woman they don't give a damn about, but we don't have an orgasm unless we love him. What's free about that?" (1962: 404). Frente a esta visión ginocentrista de continuum entre libido y sentimiento, estos dos factores permanecen desmembrados en una versión masculina que se acercaría al concepto de pornografía de Susan Griffin: "la conducta del hombre que cosifica a su compañera como materia sin alma que sólo desea poseer físicamente" (1981: 3).

La novela participaría en el controvertido debate de la sexología del siglo XX sobre el epicentro del genuino placer femenino: la vagina o el clítoris ${ }^{9}$. La narradora del cuaderno amarillo desvela que Ella alcanza el clímax sexual mediante la penetración durante su primer coito con Paul: "She immediately experienced orgasm. Vaginal orgasm, that is. And she could not have experienced it if she had not loved him. It is the orgasm that is created by the man's need for a woman, and his confidence in that need" (Lessing 1962: 200). En contraposición, su amante preferirá experimentar con la estimulación erógena de su vulva: “( $\mathrm{He})$ began to rely on manipulating her externally, on giving Ella clitoral orgasms. Very exciting. Yet there was always a part of her that resented it. Because she felt that the fact he wanted to, was an expression of his instinctive desire not to commit himself to her" (1962: 200). Según Judith Gardiner, la heterosexualidad se expresa como innata y natural en esta obra, siendo el clímax vaginal la única verdad de la biología femenina (1989: 150). La protagonista de The Shadow of

\footnotetext{
${ }^{9}$ En los cincuenta, el sexólogo norteamericano Alfred Kinsey aseverará que el clítoris es el epicentro de la respuesta sexual femenina, por lo que la satisfacción por vía vaginal sería sólo psicológica y una consecuencia más de construcciones masculinas y freudianas sobre el cuerpo y la mente de la mujer.
} 
the Third lo celebrará al considerar que se trata de la condición sine qua non para sentirse mujer -física y psíquicamente-, a la vez que deseada por el hombre. De este modo, obviará que sólo es el corolario de su preceptiva aculturación a la ideología patriarcal que defiende la superioridad del placer corporal suministrado por la vía fálica en detrimento de variantes erógenas (auto) inducidas. Sin cotejar evidencias científicas, Ella rechazará la excitación de sus genitals externos: "There is only one real female orgasm and that is when a man, from the whole of his need and desire takes a woman and wants all her response" (Lessing 1962: 200). La cópula -adictiva para mujeres libres con ella- será la no-incógnita en su mente que resuelva la ecuación matemática sobre la libido femenina: adicionar penetración y amor. Imprecisa, define el placer alcanzado gracias a esta vía coital de la mano de Paul: "Emotion and nothing else... is a dissolving in a vague, dark generalized sensation like beings wirled in a warm whirlpool" (1962: 200). Esta nebulosidad semántica de Ella obedecería a su meditación previa sobre la sexualidad. Mientras que se teoriza como racional, mecánica y prosaica en una exégesis masculina, se atesoraría como joya incognoscible e ininteligible en otra femenina, ya que residiría en el universo prelingüístico, virgen y subjetivo de la mujer:

The difficulty of writing about sex, for women, is that sex is best when not thought about, not analysed. Women deliberately choose not to think about technical sex. They get irritable when men talk technically, it's out of self-preservation: they want to preserve the spontaneous emotion that is essential for their satisfaction. Sex is essentially emotional for women. (1962: 199)

La manipulación y autoritarismo de Paul conseguirán anular la personalidad de Ella, así como ahondar en su dependencia afectiva durante los cinco años que dura este affaire. Él se mostrará tanto celoso ante la infundada amenaza de otros pretendientes como posesivo al boicotear sus facetas como profesional y madre. Introduciéndose en una dinámica masoquista, la heroína no sólo será el tercer vértice del triángulo amoroso en el cual Muriel -la esposa de su amante- es la monomanía obsesiva de su mente, sino que también ensayará con la infidelidad al acostarse con un compañero de trabajo. Sin perseguir vengarse de Paul, pretenderá experimentar en primera persona con el sexo sin 
amor o masculino conforme a su propia nomenclatura. Concluirá que sólo disfruta de su cuerpo cuando está enamorada de un único hombre. Aunque su infatuación inicial no se verá perturbada con el transcurso del tiempo, el psiquiatra sí se resentirá de las pretensiones de compromiso de la heroína tras desvanecerse la lujuria de los primeros meses de relación ilícita: "He...delivered this blow: 'But Ella, you're my mistress, not my wife. Why do you want me to share all the serious business of life with you?' Ella was angry. 'Every night you lie in my bed and tell me everything, I am your wife'. As she said it, she knew she was signing the warrant for the end" (Lessing 1962: 197-198). Por un lado, los personajes masculinos de la autora perpetúan clichés misóginos que trazan la tradicional línea divisoria entre esposa angelical y amante diabólica. Por otro, los femeninos persiguen hombres verdaderos en peligro de extinción, porque deben ser románticos y caballeros a la antigua usanza, aunque simultáneamente complacientes y deferentes con peticiones feministas contemporáneas. Sumergidos en este conflicto de género, un salomónico Paul no sólo rechazará casarse con la heroína, sino que la abandonará tanto a ella como a su mujer oficial cuando escapa para trabajar en Nigeria.

Como apógrafo de la desolación y el vacío de Anna tras su ruptura con Michael, Ella se transfigurará sentimentalmente en satélite extraviado que perdió su centro planetario y, sexualmente, padecerá la ablación de su goce sexual, sólo saciable por vía vaginal, no onanista. Dicha insatisfacción se traduce, además, en sustracción identitaria como mujer: "She had never, since he had left her, been able to achieve a vaginal orgasm; she was able to reach the sharp violence of the exterior orgasm, her hand becoming Paul's hand, mourning as she did so, the loss of her real self" (Lessing 1962: 277). De hecho, la novelista impondría el precepto de la heterosexualidad al declarar que la masturbación y el lesbianismo son sus sucedáneos, cuya práctica degenera en repugnancia y odio hacia sí misma (Wilson 1982: 65). Pese a alcanzar el orgasmo con autonomía excitando su clítoris, el autoerotismo acentúa la aversión de la heroína hacia los hombres como colectivo al constatar su adicción sexual a su antiguo amante. Sin embargo, sólo recordará su engaño, nunca sensaciones placenteras vividas junto a él: 
She begins to suffer torments of sexual desire [...] She cannot sleep, she masturbates, to accompaniment of fantasies of hatred about men. Paul has vanished completely: she has lost the warm strong man of her experience, and can only remember a cynical betrayer. She suffers sex desire in a vacuum. She is acutely humiliated, thinking that this means she is dependent on men for 'having sex', for 'being serviced', for 'being satisfied'. (Lessing 1962: 401)

Posteriormente, Ella tendrá citas amatorias esporádicas y poco reconstituyentes con varios individuos, que resquebrajarán su máxima hipocrática sobre la sexualidad femenina, aunque confirmen su dependencia de Paul. Se enfurecerá consigo misma al tomar la iniciativa de acostarse con Cy y al comprender que, sin estar enamorada, su cuerpo responde con voluptuosidad: "When he laid his large White hand on her arm, she felt her breast slift and sting. Her thighs were wet. But she had nothing in common with him [...]. This man was a healthy savage" (Lessing 1962: 288). Pese a ello, cosechará exclusivamente frustración sexual debido a la eyaculación precoz de este americano. Por otro, se indignará por todo lo contrario: su diestro amante canadiense defenderá que los actos sexuales de calidad que le brinda deberían ser suficiente aliciente que sustente su relación: "She realices that he really does not understand what is the matter with what he offers her. He has a large penis; he is 'good in bed'. And that's it" (1962: 403).

Durante este periplo, Ella investigará inconscientemente cuestiones sociológicas en torno al antagonismo entre los dos sexos. Primero, su jefe abogará por una jerarquía de género, no sólo profesional, al insinuar que si no acepta convertirse en su concubina, él encontrará otra candidata gracias al excedente de mujeres -desde solteras a divorciadas- que solicitan su compañía por el simple hecho de estar casado y tener una buena posición socioeconómica. Segundo, la joven relatará a Julia que los hombres atribuyen a las mujeres libres como ellas una absoluta disponibilidad sexual para serles infiel a sus esposas: "It's enough that their wives should go away for them to change their voices and they seem to think you're going to fall over yourself to get into bed" (Lessing 1962: 398). A este diálogo se añadiría la comicidad de opinar que la erección 
masculina se materializaría al fantasear con ellas dos como lesbianas ${ }^{10}$ en un ménage à trois. Y tercero, explorará la genealogía de la traición conyugal cuando interroga a su padre sobre su matrimonio con su madre ya fallecida. Descubrirá que, en vez de haberle enseñado artes amatorias para satisfacer juntos sus deseos, prefirió comprar los servicios de prostitutas. De este modo, la heroína descubrirá una nueva dimensión mercantilista del sexo, tan utilitaria y distante como la actitud de sus amantes hacia ella misma.

Saltando al cuaderno azul, Anna concluye que su felicidad nunca será plena por la falta de reconciliación entre sus papeles de madre y amante -dilema que vampiriza su energía vital y resquebraja su equilibrio psíquico. La responsabilidad y cuidado de los hijos recae exclusivamente en la mujer ${ }^{11}$. Las ineludibles atenciones hacia su hija Janet aportan estabilidad y alejan a la heroína del trastorno mental, pero le forzarán a abortar, muy a su pesar, encuentros sexuales con un Michael poco paciente y muy evasivo. Pese a resignarse a que su amante nunca dejará a su esposa para casarse con ella, disfruta mimándole y cocinando para él. Se angustiará cuando le arroja reflexiones sobre su duradera compatibilidad carnal, que camuflan envenenados dardos que apuntan a su progresivo distanciamiento emocional y cifran el mensaje que anunciará su inminente ruptura: " "If we have nothing else in common, we have sex'. Whenever he says this, ...I feel the pit of my stomach go cold; it is the total rejection of me... and there is a great distance between us" (Lessing 1962: 302). No se sorprenderá cuando acaba su romance, que sería tan convencional como el matrimonio al descansar ambos en la dominación masculina y la sumisión femenina. Para luchar contra el trauma generado, Anna intentará convencerse a sí misma de que está pagando un precio caro -aunque lógicopor disfrutar de su emancipación sexual, pero cae igualmente en la apatía y la depresión sin que el psicoanálisis surta los efectos balsámicos deseados. Las alternativas que se perfilan ante ella son: el colapso mental -que dilata-, el suicidio - que no se materializa, y la lucha por la supervivencia que, al igual que en el caso de Ella, sólo otro hombre transfigurado en el amor verdadero- garantizaría. A partir de este momento, las

\footnotetext{
${ }^{10}$ The Golden Notebook ni siquiera sugiere que Ella y Julia puedan mantener encuentros lésbicos.

${ }^{11}$ Richard ilustra el prototipo de hombre que descuida sus deberes como padre, pero que responsabiliza a su exmujer, Molly, y a su actual esposa, Marion, de la desatención y fracaso en la educación de sus hijos.
} 
confesiones de Anna concatenarán las perversiones sádicas de una legión miscelánea de personajes masculinos acomplejados y caricaturescos ${ }^{12} y$, sobre todo, de Saul Green.

Este escritor estadounidense se instalará como inquilino en casa de la heroína cuando su hija deja de ser un obstáculo amatorio al empezar a estudiar en un internado. Vivirán un tormentoso y tóxico affaire que acelerará el declive psíquico de Anna por culpa de dos factores: enamorarse de él y los episodios psicóticos de este hombre que infectan su ya deteriorada salud mental. Al estar soltero, su nuevo amante fracturaría el omnipresente triángulo amoroso de la obra entre el adúltero, su esposa y la mujer libre. Sin embargo, al sentirse encarcelada emocionalmente durante largas horas de espera, la protagonista espiará los diarios de Saul mientras aguarda su regreso, y descubrirá que le es igualmente infiel cuando lee su descomunal repertorio de furtivos escarceos sexuales.

Será en materia erótica donde la relación es más perjudicial para el equilibrio psíquico de Anna. Primero, se tortura al saber que su amante no desea acostarse con ella: "I was ashamed that I cared more for his not wanting to sleep with me..., than his liking me" (Lessing 1962: 501). Segundo, aprenderá a practicar juntos una nueva y destructiva modalidad del coito con el intercambio recíproco de brutalidad y odio ${ }^{13}$ : "When we quarrel, we hate each other, then sex comes out of the hate. It's a hard violent sex, like nothing I've known before" (1962: 502). Y tercero, se agravará su propensión a la fragmentación de su mente con la visualización de otra mujer -sin reconocer ser ella misma-, mientras Saul decide unilateralmente hacerle el amor tras uno de sus frecuentes altercados: "He came into my room and made love to me. It wasn't real love-making, he had decided he would make love. The creature inside me who is the woman in love was not implicated, refused to be lied to" (1962: 491). De hecho, la escisión patógena de su personalidad dividida entre la mujer independiente y el ama de casa subyugada a sus irreconciliables roles de madre y amante degeneran en alteridad esquizoide. Ofreciendo amor y sólo recibiendo dolor a cambio, Anna se

\footnotetext{
${ }^{12}$ Al igual que Ella y Paul son los dobles de Anna y Michael, se hallaría una similar sucesión de amantes de la primera en la vida de la segunda - la real y creadora-, aunque sean evocados con otros nombres.

${ }^{13}$ En su definición del erotismo como la parte integrante de la sexualidad humana dotada de lenguaje y en las antípodas de la reproducción, Georges Bataille sostiene que la violencia es su dominio (2011: 16), en consonancia con la agresividad de Saul que infecta su relación sentimental con Anna.
} 
someterá a la dimensión pornográfica de la sexualidad masculina y, con ello, su masoquismo se agudizará. Se resignará al engaño al temer la soledad. De hecho, la presencia contendiente de Saul resultará menos insoportable que sus frecuentes ausencias. Cuando su affaire se tambalea, este inquilino le hará daño al reconocer que disfruta siendo hombre en una sociedad donde la mujer es considerada como ciudadana de segunda clase, y sentencia que la heroína es una mujer tradicional debajo de su fachada de solvencia económica y prodigalidad sexual: "You're a real domestic woman, you ough tto be married to a nice settled husband somewhere" (1962: 498). Esta afirmación encubriría el pesimismo de Lessing respecto a la no-liberación del género femenino debido a sus persistentes fantasías monógamas ya su dependencia emocional de hombres, aún misóginos, egoístas y déspotas.

Sin embargo, Anna iniciará su recuperación psicológica al tomar conciencia de que su pareja es nociva para su salud mental y de que necesita desembarazarse de sus ocupaciones indeseadas como sirvienta, camarada, confidente, terapeuta y madre -más que amante ardiente y apetecible-, que consiente los coqueteos sexuales de Saul con mujeres rivales. Pero será él mismo quien propicie su rehabilitación psicológica y social. Le exhorta a no redactar en sus diarios cuánto le odia por culpa de sus infidelidades, sino a reconstruir su personalidad y experiencia personal -antes fragmentada y dispersa-, a través del último cuaderno: el dorado. Con anterioridad a marcharse, alentará a la heroína a retomar su carrera literaria para superar su bloqueo creativo. Recíprocamente, se brindarán la primera línea de sus futuras novelas. La paradoja narrativa es que el regalo del estadounidense sea el primer párrafo de Free Women I con el que Anna comenzó a redactar el conjunto de la obra: "The two women were alone in the London flat" (Lessing 1962: 25), referido a ella misma y a Molly.

La última sección de esta historia corta separada en cinco partes simbolizará la reconciliación de la protagonista con el género masculino al imaginar, desde las enseñanzas del anterior diario dorado, su último flirt con un hombre ${ }^{14}$. Aprenderá que la ruptura sentimental es, de nuevo, ineludible pero, esta vez, no será tan traumática.

\footnotetext{
${ }^{14}$ Free Women V no esclarece si este hombre es el nuevo amante de Anna o el doble inventado de Saul.
} 
Asimismo, dicha quinta sección será el epílogo que clausure el conjunto de The Golden Notebook: la integración de sus heroínas en la sociedad sin que, por el contrario, hayan resuelto las tribulaciones de su vida amorosa y sexual. Molly se casará de nuevo para asegurar su bienestar económico, mientras que Anna desterrará sueños de estabilidad amorosa y vetará que Frontiers of War sea adaptada al cine por el Establishment. Optará por la actividad profesional en busca de la autorrealización personal y el alivio de la catarsis mental. En lugar de perseverar en la literatura -peligrosa por su inclinación introspectiva-, se reinsertará al mundo laboral y se dedicará oficialmente al prójimo -no oficiosamente a un sólo hombre- como trabajadora social que orienta a jóvenes delincuentes y consejera matrimonial afiliada al partido laboralista.

Toda la novela enaltecerá la solidaridad femenina como terapia de grupo para cicatrizar las heridas psicológicas infligidas por el hombre. Su última línea: "The two women kissed and separated" (Lessing 1962: 576) demostrará que el alejamiento físico -temporal o definitivo- de estas dos amigas al escoger rumbos distintos no entrañará el divorcio afectivo entre ellas, en contraste con el común desenlace hostil del romance heterosexual. Sin embargo, también aparecerán mujeres contrincantes en The Golden Notebook. Frente a la esposa y otras jóvenes solteras, Doris Lessing no retratará a Anna/Ella como figura paradigmática de la feminista autosuficiente y empoderada, sino como la amante o la Otra quien, tras su fracaso matrimonial, cree erróneamente ser soberana de su mente y cuerpo. Aunque satisfaga su libido con plenitud, supere remordimientos puritanos al acostarse con hombres casados o sea ella misma infiel, perpetúa el (ana) crónico arquetipo de víctima o mujer caída por culpa de su sumisión y subordinación emocional ante un hombre que, egoístamente, tortura a su compañera con su explotación sexual, manipulación psicológica y el castigo de su huida final. Pese a ello, la autora monitorizará sus cambios y evolución hacia el autoconocimiento y la aceptación de sí misma. Este proceso estará plagado de altibajos, retrocesos, descensos en la neurosis y obsesiones del pasado, pero también de valentía para compaginar todos sus papeles (Durán 2000: 104). En definitiva, Doris Lessing abrazaría la idea de que la vida es una carrera de fondo donde su heroína suele perder, pero debe ganar en fortaleza mental como requisito previo para explorar territorios nuevos hacia una futura plenitud 
sexual y emocional; no para reconquistar otros ya conocidos que pronosticarían reincidentes reverberaciones de un pasado traumático.

\section{La exploración escatológica del cuerpo femenino}

Muchas lectoras reconocerán haber vivido experiencias sexuales y sensaciones orgánicas que serían análogas a las leídas en The Golden Notebook y que, por primera vez, se expresarán narrativamente desde un soberano punto de vista femenino: diálogos, acciones, meditaciones y descripciones sobre la anatomía del hombre y la mujer, o sobre encuentros eróticos satisfactorios y decepcionantes. Esta obra transgredirá, asimismo, tabúes al reproducir aspectos biológicos y escatológicos que impactarán al público y la crítica. Dicha dimensión fisiológica cobrará una gran envergadura dentro de su conjunto de la narrativa de Lessing no por ser soez, coloquial y heterodoxa, amoral y desconocida para la condición humana, sino porque nunca antes fue relatada de forma explícita en la literatura y, aún menos, por una mujer. Para aproximarse a la intimidad femenina, la novelista británica romperá con siglos de silencio artístico al redactar las reflexiones de Anna en torno a la menstruación, suceso cotidiano y casi intrascendente, aunque chocante textualmente porque, hasta entonces, sólo se había sugerido mediante tropos y símbolos identificados por la crítica literaria feminista. Con claridad gráfica y bajo el mismo modus operandi mensual, la heroína actúa al percibir la hemorragia del periodo, cuya llegada imprevista considera inoportuna. Conforme al adoctrinamiento educativo del reinante discurso científico, asocia este fenómeno natural con alteraciones nerviosas y cambios de estado anímico: "I stuff my vagina with the tampon of cottonwool [...] If I had not noticed my period had started, I would not be feeling nearly so irritable" (Lessing 1962: 303). No sólo admitirá la molestia física y emocional de este trance periódico inherente a la anatomía femenina y que condiciona su vida adulta, sino que igualmente confesará la repugnancia que le causa el olor de la sangre 
menstrual ${ }^{15}$. En cambio, preferirá sensaciones olfativas producidas por otras secreciones orgánicas vinculadas tanto al cuerpo de la mujer como al del hombre: "I don't mind my own immediate lavatory smells; I like the smell of sex, of sweat, of skin, or hair. But the faintly dubious, essentially stale smell of menstrual blood, I hate [...] Yet for two days I have to deal with this thing from outside - a bad smell, emanating from me" (1962: 304). Según avanza The Golden Notebook, la descripción de sus genitales y las náuseas sobrevenidas por los procesos biológicos de su sexo diagnosticarían el empeoramiento de su cuadro clínico. Confirmarían una disociación entre su mente y sus atributos femeninos, o, por el contrario, su cordura al rebelarse contra imposiciones naturales que, aunque manipuladas para celebrar el cariz falocentrista de la sociedad patriarcal, coartan su libertad personal como individuo: "I realized my body was distasteful to me [...] My wet sticky centre seemed disgusting, and when I saw my breasts all I could think of was how they were when they were full of milk, and instead of this being pleasurable, it was revolting" (1962: 532).

El informe detallado de los coitos, orgasmos, periodos o síntomas del trastorno mental de Anna no ilustrarían la llamada Écriture Féminine ${ }^{16}$, focalizada en el cuerpo de la mujer, al no contribuir a afianzar su empoderamiento, sino a su anulación a través del lenguaje (Krouse 2006: 44). Pese a ello, la novela de Doris Lessing saltará de la singularidad en la introspección psicológica de su heroína hasta la representatividad con respecto a la colectividad a la hora de reflejar la conciencia y vivencias de un gran porcentaje de población femenina en un marco espacio-temporal determinado. Estas mujeres se sentirían identificadas, por un lado, con los personajes secundarios dela obra: Molly y Marion. Y por otro, con Anna Wulf: sus concomitantes papeles sociales madre, divorciada, militante, amante o profesional-, su doble de ficción -Ella-, o sus múltiples personalidades, fruto de su trastorno esquizoide. Mediante esta pléyade de desafinadas voces polifónicas, Lessing sostendría que, esté soltera, casada o separada, la situación afectiva y sexual de la mujer en la segunda mitad del siglo XX no difiere

\footnotetext{
${ }^{15}$ Para resaltar los prejuicios patriarcales en torno a la menstruación en la historia, Bataille la define como tabú de la sexualidad humana y manifestación de su violencia que genera una mancha (2011: 56).

${ }^{16}$ Corriente de la teoría feminista francesa de la segunda mitad del siglo XX que aboga por la transcripción textual del cuerpo de la mujer y sus diferencias biológicas con respecto al hombre.
} 
sustancialmente en relación a su estatus público, y que ésta tiende a encauzarse hacia vías neuróticas y autodestructivas ${ }^{17}$. En consonancia, las confidencias entre Marion y Anna delataría su envidia mutua: la primera ansía la autonomía de la segunda, mientras que ésta última desea la seguridad y confort de la pareja de Richard. En definitiva, una y otra no serían más figuras antagónicas, sino dos siluetas que se reflejan en un mismo espejo, pese a su enfrentamiento ideológico, social y literario por imperativo masculino.

\section{Conclusión}

Para Simone de Beauvoir erradicar la dependencia económica de la mujer no es suficiente para garantizar la igualdad de género, únicamente alcanzable mediante cambios culturales, sociales y morales de gran calado (1949: 645). Novelista, autobiógrafa, historiadora, periodista, filósofa, politóloga y sibila, Doris Lessing madurará una literatura exploratoria que revele la identidad femenina. Su prosa estará embellecida por iridiscentes tonalidades ideológicas de los años sesenta del siglo XX, entre su renegada apología del feminismo y su pesimismo sobre la condición humana; pero estará igualmente minada por vacilaciones y contradicciones poderosamente artísticas y desmitificadoras. Apoyándose como escritora en estructuras formales y temáticas posmodernas -la fragmentación, la polifonía o la heterogeneidad-, desaparecerían también los márgenes entre realidad y ficción que separan a Doris Lessing de sus dos criaturas de escalonada ficcionalidad: Anna y Ella. Al unísono, las tres sugerirán que la libre experimentación con la sexualidad femenina no se correlaciona todavía con otra más amplia, ambiciosa y placentera -la de género-, en el contexto espaciotemporal de la Inglaterra de posguerra. Si bien una trayectoria textual positiva dentro de su obra avanza hacia la democratización de la libido de la mujer y su regenerativa integración social con su acceso a la vida laboral, ésta cohabita con otra negativa. La satisfacción sexual sólo por vía coital y un romanticismo (im) propio para

\footnotetext{
${ }^{17}$ La historia corta de Lessing "To Room Nineteen" (1963) profundiza en aspectos sexuales y afectivos de una esposa casada, asediada como Anna Wulf por la locura y la dependencia emocional del hombre.
} 
militantes feministas, que degenera en victimización y sometimiento, evidenciarían el persistente influjo de la sociedad patriarcal y la primacía masculina. No obstante, la temática de la sexualidad femenina será un vaso comunicante con las inquietudes de Doris Lessing, quien coronaría a The Golden Notebook como acto terapéutico o vomipurgante para ella misma y la globalidad de la población femenina. Nuestra mirada retrospectiva desde 2013, el año de su fallecimiento, no sólo invita al homenaje a esta eminente escritora británica, sino también a la inequívoca conclusión de que su corpus literario -en especial la canónica obra explorada en este artículo- contribuirá, a su pesar o no, a la paulatina normalización de las relaciones entre ambos sexos dentro del marco del inacabado reconocimiento de los derechos civiles de la mujer durante la segunda mitad del siglo XX, mediante la visibilidad textual de procesos biológicos, cognitivos y emocionales de su soma y psique (ir) reconciliadas.

\section{Referencias bibliográficas}

Bataille, Georges. 2011. L'Érotisme. Paris: Les Éditions de Minuit.

Baumeister, Roy F. y Jean M. Twenge. 2002. "Cultural Supression of Female Sexuality”. Review of General Psychology 6, II: 166-203.

Beauvoir, Simone de. 1949. Le Deuxième Sexe, vol. II: L'Experience Vécue. Paris: Gallimard.

Brooks, Ellen W. 1973. "The Image of Woman in Lessing's The Golden Notebook". Critique 15, I: 101-109.

Burguess, Anthony. 1967. The Novel Now: A Guide to Contemporary Fiction. New York: Norton.

DuPlessis, Rachel Blau. 1980. "For the Etruscans". The Pink Guitar: Writing as Feminist Practice. New York: Routledge. 1-19.

Durán Giménez-Rico, Isabel. 2000. "Doris Lessing: la interminable búsqueda del yo a través de Doris Lessing, Martha Quest, y Anna Wulf”. Atlantis 22, I: 85-108.

Foucault, Michel. 1976. The History of Sexuality, vol. I: An Introduction. New York: Pantheon Books. Vintage. 1984. The History of Sexuality, vol. II: The Use of Pleasure. New York: 
Gardiner, Judith Kegan. 1989. Rhys, Stead, Lessing, and the Politics of Empathy. Bloomington \& Indianapolis, IN: Indiana University Press.

Greene, Gayle. 1994. Doris Lessing: The Poetics of Change. Ann Arbor, MI: University of Michigan Press.

Griffin, Susan. 1981. Pornography and Silence: Culture's Revenge against Nature. New York: Harper \& Row.

Henke, Suzette A. 2000. Shattered Subjects: Trauma and Testimony in Women's LifeWriting. New York: St. Martin's Press.

Krouse, Tonya. 2006. "Freedom as Effacement in The Golden Notebook: Theorizing Pleasure, Subjectivity, and Authority". Journal of Modern Literature 29, III: 3956.

Lessing, Doris. 1962. The Golden Notebook. London: Harper Perennial. 1972. "Preface". The Golden Notebook. London: Harper Perennial.

Showalter, Elaine. 1985. The Female Malady: Women, Madness and English Culture, 1830-1980. London: Virago.

Spencer, Sharon. 1973. "Femininity' and the Woman Writer: Doris Lessing's The Golden Notebook and the Diary of Anaïs Nin". Women's Studies 1, III: 247-257.

Wilson, Elizabeth. 1982. "Yesterday's Heroines: on Rereading Lessing and de Beauvoir". Notebooks/Memoirs/Archives: Reading and Rereading Doris Lessing. Ed. Jenny Taylor. Boston \& London: Routledge \& Kegan Paul. 57-74. 